\title{
Radiation Genetics of Sesame-Part I
}

\author{
Meiotic Chromosome Aberrations induced by Absorbed \\ Radioactive Phosphorus*
}

TEISAKU KoBAYASHi

Biological Institute, Faculty of Literature and Science, Toyama University, Japan,

\section{Received August 27, 1957}

To produce mutations, or chromosome aberrations, X-rays radiated externally on organisms have been used more frequently than other types of radiation and many reports on the genetic effect induced by X-rays have been published.

Recently, through the abundant production by atomic reactors of radioactive isotopes of various elements, it has been possible to carry on studies of cytogenetics utilizing not only external radiation sources but also internal radiation sources. Some papers in this field have been published, (Giles 1947, Giles and Bolomey 1948, Arnason 1948, Arnason et al. 1948, Kobayashi 1954 a, b and 1955).

Since 1953, the author has studied the cytogenetic effect and production of mutants in sesame (Sesamum indicum L) by using ionizing radiations in varying degrees. This paper describes chromosome aberrations in sesame microsporogenesis induced by $\beta$-rays emitted from absorbed radioactive phosphorus $\left(\mathrm{P}^{32}\right)$.

\section{Materials and methods}

Two forms of Sesamum indicum L., $\mathrm{B}_{1} \mathrm{D}$ and WD each with $2 \mathrm{n}=26$ (see Kobayashi and Shimamura 1952) were used in the present study. In each form the seeds were of a line derived from a single plant produced by self-crossing which had been begun in 1947.

The radiophosphorus ( $\mathrm{P}^{32}$ ) used was supplied by the Oak Ridge National Laboratory, Tennessee, U.S.A. in chemical form $\mathrm{P}^{320_{4}}$ in weak $\mathrm{HCl}$ at $\mathrm{Ph}$ values between $I$ and 4 . To produce chromosome breaks in meiosis, the following methods of $\mathrm{P}^{32}$ treatment were employed :

\section{Method I-Stem Injection \\ Method II-Radicle Immersion \\ Method III-Leaf Immersion}

Prior to examining chromosome aberrations, the author had preliminarily carried out the following experiments in order to find the distribution of $\mathrm{P}^{32}$ in plant tissue. A growing plant with many flower buds and some young capsules were selected and $1 \mathrm{ml}$. of $\mathrm{P}^{32}$ solution containing $10 \mu \mathrm{c}$ at initial radioactivity was introduced into the

\footnotetext{
* The expense of this work was defrayed in part by a Grant-in-aid from the Science Research Fund, Ministry of Education (Subject Nos. 10748 and 407042 for 1954 and 1955 respectively).
} 
stem with an injector. The injection was made about half way up the stem in a carefully selected region of the vascular bundle situated in the corner of the stem (Fig. 1). Three days after injection, the extent of $\mathrm{P}^{32}$ distribution and degree of ac-

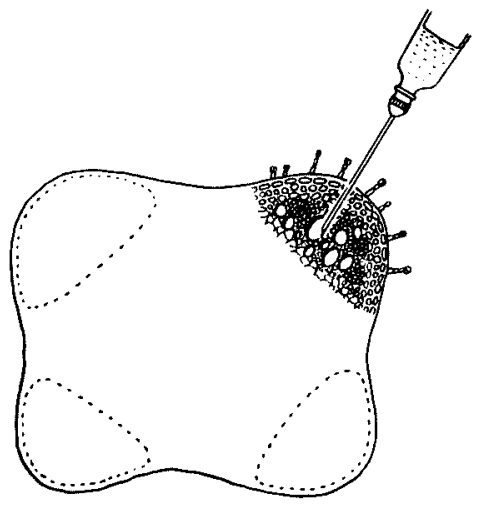

Fig. 1. Schematic diagram showing Method I (Stem injection).

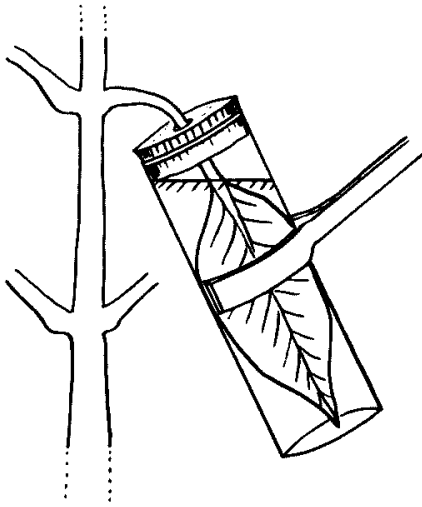

Fig. 2. Schematic diagram showing Method II (Leaf immersion).

cumulation in several parts of the plant were investigated by using Geiger-Muller counter. Before taking measurements, the treated plant was divided, separating the upper and lower parts respectively, on the basis of the stem region where the injection had been made. And the incinerated materials obtained from ten parts of the plant were prepared and measurements taken of $\mathrm{P}^{32}$ activities. The results are given in Table 1 appended.

Table. 1. $\mathrm{P}^{32}$ distributions in an injected plant $(10 \mu \mathrm{c})$.

\begin{tabular}{|c|c|c|c|c|c|c|}
\hline & Parts of plant & $\begin{array}{l}\text { Wet weight } \\
\text { (gm.) }\end{array}$ & Total count $/ \mathrm{min}$. & $\mathrm{c} / \mathrm{min}$. per $\mathrm{gm}$. & $\% / \mathrm{gm}$ & Ratio \\
\hline \multirow{7}{*}{$\begin{array}{l}\text { Upper } \\
\text { parts }\end{array}$} & Bud & 1.0 & 471.1 & 471.1 & 12.1 & \multirow{7}{*}{9.0} \\
\hline & Flower & 1.4 & 654.4 & 467.4 & 12.1 & \\
\hline & Leaf & 11.8 & 5665.6 & 480.1 & 12.4 & \\
\hline & Stem & 8.8 & 6245.0 & 709.7 & 18.3 & \\
\hline & $\begin{array}{l}\text { Seed (immatu- } \\
\text { re) }\end{array}$ & 2.5 & 1045.4 & 418.2 & 10.8 & \\
\hline & $\begin{array}{l}\text { Capsule (with- } \\
\text { out seed) }\end{array}$ & 5.7 & 24.14 .3 & 423.6 & 10.9 & \\
\hline & $\begin{array}{l}\text { Capsule (with } \\
\text { seed) }\end{array}$ & 4.5 & 2363.2 & 525.2 & 13.5 & \\
\hline \multirow{3}{*}{$\begin{array}{l}\text { Lower } \\
\text { parts }\end{array}$} & Leaf & 12.6 & 2018.8 & 160.2 & 4.1 & \multirow{3}{*}{1.0} \\
\hline & Stem & 30.2 & 5446.8 & 180.4 & 4.7 & \\
\hline & Root & 7.6 & 322.4 & 42.4 & 1.1 & \\
\hline Total & & 86.1 & 26647.0 & 3878.3 & 100.0 & \\
\hline
\end{tabular}

As shown in Table 1, most of the $\mathrm{P}^{32}$ injected into the stem moved quickly into the upper parts and accumulated in them selectively in meristematic parts (growing buds, flower buds, young leaves and capsules, etc.). Such evidence was recognized 
also in many autoradiographs obtained from plants treated with other similar methods (P1. I, Figs. 1-4).

Thus it seemed to the author that Method I was suitable for production of chromosome breaks by internal radiation of $\beta$-rays from the $\mathrm{P}^{32}$ which had been injected. Various $\mathrm{P}^{32}$ solutions, ranging from 0.005 to $1.5 \mu \mathrm{c}$ per $\mathrm{ml}$. at initial activity, were injected into stems of plants before the flowering stage.

Methods II and III were carried on without preliminary experiments, and only two for each method were made. In Method If, germinating seedlings with a radicle measuring between 5 to $10 \mathrm{~mm}$. in length, were immersed for four or five days in P32 solution containing 0.6 or $1.2 \mu \mathrm{c}$ per $\mathrm{ml}$. Fig. 5 , Plate I, is an autoradiograph obtained from material sectioned after treatment. After treatment seedlings were planted in the field.

Two plants having many flower buds were prepared for Method III. A leaf situated near the middle of the stem was placed into a test tube in which there was a $50 \mathrm{ml}$. solution containing 0.6 or $1.2 \mu \mathrm{c}$ of $\mathrm{P}^{32}$, and kept there for four days (Fig. 2). Then the leaf was treated with $1.2 \mu \mathrm{c}$ and the leaf surface which had been contaminated by $\mathrm{P}^{32}$ was carefully rinsed and used autoradiographic material (Pl. I, Fig. 6).

Solution of Navashin's or 2BD (La Cour 1931) was used for fixation for cytological studies. Almost all flower buds of the plants treated with Method I were fixed at seven days after treatment, but a few were fixed daily during the first week for study on the relation between frequency of chromosome aberration and time after treatment. Taken from plants to be treated with Method II, some fresh buds in early stage were chosen for fixation, and from those treated with Method III buds were fixed at six or seven days after treatment.

Sections with thickness of 10 to $12 \mu$ were cut by paraffin method and stained in haematoxylin or crystal violet. For some materials, acetic-orcein squash method was also used.

\section{Experimental results}

The chief purpose throughout each experiment was to observe cytologically the chromosomes at stages from metaphase to anaphase in the first nuclear division of the meiosis, and some aberrant figures in the second division and in the tetrad stage were observed additionally.

For the sake of convenience throughout the present investigation, aberrant meiotic chromosomes (figures observed at $\mathrm{MI}$ and $\mathrm{AI}$ ) were grouped as follows:

At MI : Formation of

Type 1-chain or ring configuration consisting of all or almost all complements Type 2-frying-pan configuration consisting of all or almost all complements Type 3-some fragments

Type 4-mixed variously among Types 1,2 , and 3 
Type 5-others

At AI : Representation of

Type 1-laggard chromosomes

Type 2-chromosomal bridges

Type 3-chromosomal fragments

Type 4-mixed variously among Types 1,2 , and 3

Type 5-others

Further, for aberrant configurations at MI, the following categories and symbols are used : -4- (chain-of-four), (4) (ring-of-four), (4)-4-(frying-pan, combined with chain and ring.of-four), etc.

1. Aberrations induced by Method I (Stem injection).

At $\mathrm{MI}$ in the PMCs from the untreated materials, thirteen bivalents (13II) were clearly seen with some secondary pairings (P1. II. Fig. 7, Kobayashi and Shimamura 1952). On the contrary, at PMCs of the treated plants, various aberrant chromosomes were frequently observed (Figs. 3-5, P1. II. Figs. 8-12). Data on frequency of abrormal configurations are presented in Table 2.

Table 2. Frequencies of chromosome aberrations at MI induced by Method I (Stem injection).

\begin{tabular}{|c|c|c|c|c|c|c|c|c|c|}
\hline \multirow{2}{*}{$\begin{array}{c}\text { Initial } \\
\text { activity } \\
\text { ( } \mu \text { c. } / \mathrm{ml} .)\end{array}$} & \multirow{2}{*}{$\begin{array}{l}\text { Num. of } \\
\text { PMC } \\
\text { observed }\end{array}$} & \multirow{2}{*}{$\begin{array}{l}\text { Num. of } \\
\text { normal } \\
\text { PMC }\end{array}$} & \multicolumn{6}{|c|}{ Num. of PMC with aberrations } & \multirow{2}{*}{$\%$} \\
\hline & & & Type 1 & Type 2 & Type 3 & Type 4 & Type $5^{11}$ & Total & \\
\hline 1.5 & 143 & 5 & 55 & 23 & 10 & 47 & $3(\mathrm{~A}, 2 \mathrm{C})$ & 138 & 96.5 \\
\hline 0.8 & 120 & 17 & 41 & 15 & 15 & 31 & $1(B)$ & 103 & 85.8 \\
\hline 0.6 & 95 & 19 & 29 & 17 & 0 & 27 & $3(\mathrm{~A}, \mathrm{~B}, \mathrm{C})$ & 76 & 80.0 \\
\hline 0.5 & 103 & 30 & 31 & 16 & 5 & 19 & $2(B, C)$ & 73 & 70.9 \\
\hline 0.3 & 110 & 48 & 23 & 8 & 2 & 29 & 0 & 62 & 56.4 \\
\hline 0.15 & 123 & 64 & 22 & 9 & 3 & 24 & $1(B)$ & 59 & 48.0 \\
\hline 0.1 & 67 & 33 & 20 & 4 & 0 & 20 & 0 & 34 & 50.7 \\
\hline 0.08 & 107 & 71 & 13 & 1 & 4 & 17 & $1(B)$ & 36 & 33.6 \\
\hline 0.06 & - & - & - & - & - & - & - & - & - \\
\hline 0.05 & 94 & 78 & 1 & 1 & 0 & 4 & 0 & 6 & 6.4 \\
\hline 0.03 & 119 & 89 & 10 & 2 & 3 & 15 & 0 & 30 & 2.5 \\
\hline 0.015 & 126 & 117 & 2 & 1 & 1 & 5 & 0 & 9 & 7.1 \\
\hline 0.01 & 59 & 57 & 0 & 1 & 0 & 1 & 0 & 2 & 3.4 \\
\hline 0.008 & 107 & 107 & 0 & 0 & 0 & 0 & 0 & $\overline{0}$ & 0.0 \\
\hline 0.006 & 45 & 44 & 0 & 0 & 0 & 1 & 0 & 1 & 2.2 \\
\hline 0.005 & 160 & 160 & 0 & 0 & 0 & 0 & 0 & 0 & 0.0 \\
\hline Cont. & 212 & 212 & 0 & 0 & 0 & 0 & 0 & 0 & 0.0 \\
\hline
\end{tabular}

1) A...The PMC with many univalents or minutes.

B...The PMC with multipolar spindles.

C...The PMC with a mass induced by fusion of all complements

Even with an initial radioactivity as low as $0.1 \mu \mathrm{c}$ per mi. of original solution, aberration frequencies were considerably high (50.7\%), and in proportion to an increase 
of activity of more than $0.1 \mu \mathrm{c}$, formations of chromosome chain, ring or frying-pan consisting of many chromosomes or of all the complements were more abundant (Table 2, Figs. 3-4, PI. II. Figs. 7-11).

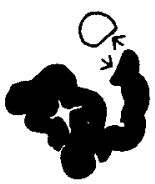

3

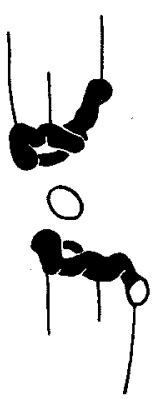

7

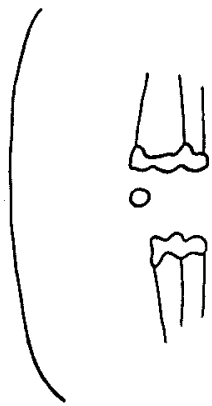

11

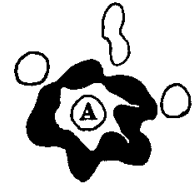

4

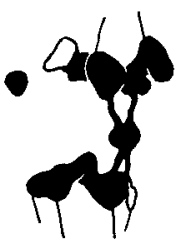

8

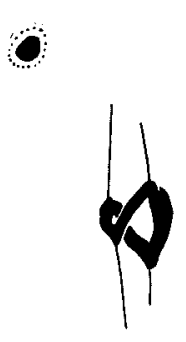

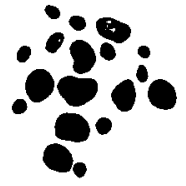

5

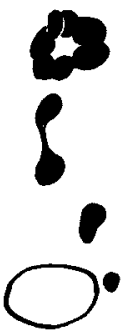

9

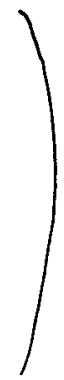

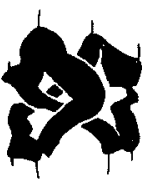

6

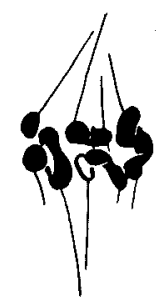

10

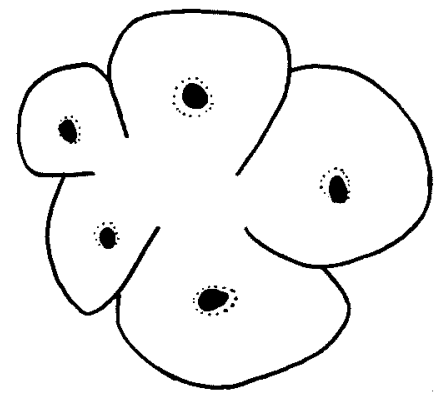

12

Figs. 3-5. Metaphase 1. ( $\times 1500)$

3. Frying-pan and fragment without reunion at each broken end (indicated by arrow) $(0.5 \mu . c)$.

4. (1B) $+(-4-)+3_{\text {II }}$ (the " $A$ " chromosome at center is indicated by A) $(0.1 \mu . c)$.

5. Bivalents, univalents and minutes $(1.5 \mu \mathrm{c})$.

Figs. 6-9. Anaphase 1. $(\times 1500)$

6. A typical zig-zag-shaped large ring consisting of all complements at early anaphase ( $0.6 \mu . c)$.

7. Separated two frying-pans symmetically with polycentrics in each and one acentric fragment at center $(0.1 \mu \mathrm{c})$.

8. Sticky bridges, due to physiological effect, and fragments $(0.6 \mu \mathrm{c})$.

9. One single bridge, two fragments and large ring arrived at one pole (upper) $(0.8 \mu . \mathcal{C})$.

Fig. 10. Aberrations of chromosomes at early anaphase of a EMC (0.5 uc).$\times 1500$

Fig. 11. Irregularities in the second division, and one micronucleus at upper center $(0.3 \mu \mathrm{c})$. $\times 1000$

Fig. 12. Abnormal cleavages (divided into five) at early tetrated stage $(1.2 \mu \mathrm{c}) . \times 500$ 
It is often found that in some preparations, chromosome " $\mathrm{A}$ ", the largest karyotypically of the complements does not show any aberration even though all the other twelve chromosomes do show aberrations at comparatively high activities (1. 5-0.1 $\mu$ c, Fig. 4, Pl. II. Figs. 8-9). Fragments produced by chromatid or isochromatid break were frequently seen (Fig. 3, P1. II. Fig. 8), but a chromosomal mass produced by fusion of the complements (Pl. II. Fig. 12), univalents or minutes (infinitesimal fragment, Fig. 5), and tripolar spindles (Pl. II. Fig. 13) were rarely observed (Table 2).

Aberrations on chromosome separation at AI are summarized in Table 3 . Usual-

Table 3. Frequencies of aberration at AI induced by Method I (Stem injection).

\begin{tabular}{|c|c|c|c|c|c|c|c|c|c|}
\hline \multirow{2}{*}{$\begin{array}{c}\text { Initial } \\
\text { activity } \\
(\mu \mathrm{c.} . / \mathrm{ml} .)\end{array}$} & \multirow{2}{*}{$\begin{array}{l}\text { Num. of } \\
\text { PMC } \\
\text { observed }\end{array}$} & \multirow{2}{*}{$\begin{array}{c}\text { Num. of } \\
\text { normal } \\
\text { PMC }\end{array}$} & \multicolumn{6}{|c|}{ Num. of PMC with aberrations } & \multirow{2}{*}{$\%$} \\
\hline & & & Type 1 & Type 2 & Type $\mathbf{3}$ & Type 4 & Type $5^{1 / 2}$ & Total & \\
\hline 1.5 & 111 & 0 & 65 & 30 & 6 & 8 & $2(\mathrm{~A} ?, \mathrm{C})$ & 111 & 100.0 \\
\hline 0.8 & 107 & 4 & 72 & 13 & 2 & 15 & $1(\mathrm{~A})$ & 103 & 96.3 \\
\hline 0.6 & 89 & 8 & 60 & 7 & 0 & 13 & $1(\mathrm{~B})$ & 81 & 91.0 \\
\hline 0.5 & 127 & 25 & 47 & 21 & 3 & 31 & 0 & 102 & 80.3 \\
\hline 0.3 & 88 & 20 & 38 & 7 & 1 & 20 & $2(B, C)$ & 68 & 77.3 \\
\hline 0.15 & 78 & 32 & 21 & 8 & 0 & 17 & 0 & 46 & 58.9 \\
\hline 0.1 & 36 & 16 & 15 & 2 & 1 & 2 & 0 & 20 & 55.5 \\
\hline 0.08 & 100 & 69 & 25 & 0 & 2 & 4 & 0 & 31 & 31.0 \\
\hline 0.06 & 32 & 28 & 3 & 0 & 1 & 0 & 0 & 4 & 12.5 \\
\hline 0.05 & 73 & 66 & 5 & 0 & 0 & 1 & $1(\mathrm{~A})$ & 7 & 9.6 \\
\hline 0.03 & 98 & 59 & 26 & 3 & 0 & 7 & $2(B, C)$ & 38 & 3.8 \\
\hline 0.015 & 103 & 97 & 5 & 0 & 0 & 1 & 0 & 6 & 5.8 \\
\hline 0.01 & - & - & - & - & - & - & - & - & - \\
\hline 0.008 & 86 & 85 & 1 & 0 & 0 & 0 & 0 & 0 & 1.2 \\
\hline 0.006 & 57 & 57 & 0 & 0 & 0 & 0 & 0 & 0 & 0.0 \\
\hline 0.005 & 95 & 93 & 2 & 0 & 0 & 0 & 0 & 2 & 2.1 \\
\hline Cont. & 117 & 117 & 0 & 0 & 0 & 0 & 0 & 0 & 0.0 \\
\hline
\end{tabular}

1) A...The PMC with bent spindle.

B...The PMC with sticky bridge.

C...The PMC with chromosomes divided into three poles.

1y, large rings formed by interchanges are zig-zag in shape in an early stage (Fig. 6). Many anaphase irregularities are almost exclusively laggard (Type 1) or of mixed type (Type 4), and laggard chromosomes or fragments were, in general, acentrics (Table 3, Figs. 7-9, Pl. II. Figs. 14-15). The next most common aberrations the bridges (P1. II. Fig. 14). At early AI, two frying-pan shape were evenly separated moving toward oposite poles (Fig. 7); such a figure however, is very rare. Bridges varied in number from one to five per cell, a single bridge more common while double or triple bridges resulting from polycentrics are comparatively few (PI. II. Fig. 14). "Sticky" bridges caused by physiological effects of radiation are occa- 
sionally observed (Fig. 8).

Acentric fragments are more recognizable in the late anaphase: these fragments often remained in the neighbourhood of the nuciear plate or outside of spindle regions (Fig. 7, Pl. II. Figs. 14-15). Fragments remaing in the cytoplasm, were usually converted into micronuclei, and were often observed in the second division (Fig. 11). Cells at tetrad stage and pollen grains from treated plants show many abnormalities in size, shape and number (Fig. 12, Pl. II. Fig. 16).

It was noticeable that some tapetal tissues treated with more than $0.8 \mu \mathrm{c}$ exhibited a degeneration caused by their cytolysis; the degenerated parts of the tisseu were deeply stained with haematoxylin or crystal violet. In an extreme case, there was no pollen mother cell in the pollen sacs (Pl. II. Fig. 17). In additional observations at AI treated EMCs as well as treated PMCs, separation irregularities of the chromosomes were clearly seen (Fig. 10).

Further, the relation between frequency of anaphase irregularity and time (in days) after treatment using four different activities of 0.1 to $1.5 \mu \mathrm{c}$, is given in Table 4 and Figure 13. To furnish the data, the maximum frequency of irregularities for

Table 4. Comparison of aberration frequency (\%) at AI between radioactivity and time after treatment (Method I).

\begin{tabular}{|c|c|c|c|c|}
\hline 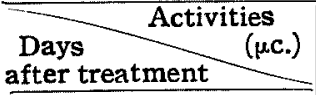 & 1.5 & 0.8 & 0.5 & 0.1 \\
\hline 1 & 73.1 & 57.4 & 40.7 & 32.9 \\
\hline 2 & 92.5 & 88.1 & 70.9 & 47.1 \\
\hline 3 & 79.8 & 91.3 & 56.6 & 39.1 \\
\hline 4 & 86.3 & 75.5 & 55.2 & 41.2 \\
\hline 5 & 83.3 & 65.3 & 47.1 & 33.2 \\
\hline 6 & 77.6 & 68.2 & 34.4 & 40.0 \\
\hline 7 & 81.5 & 63.6 & 37.2 & 30.7 \\
\hline
\end{tabular}

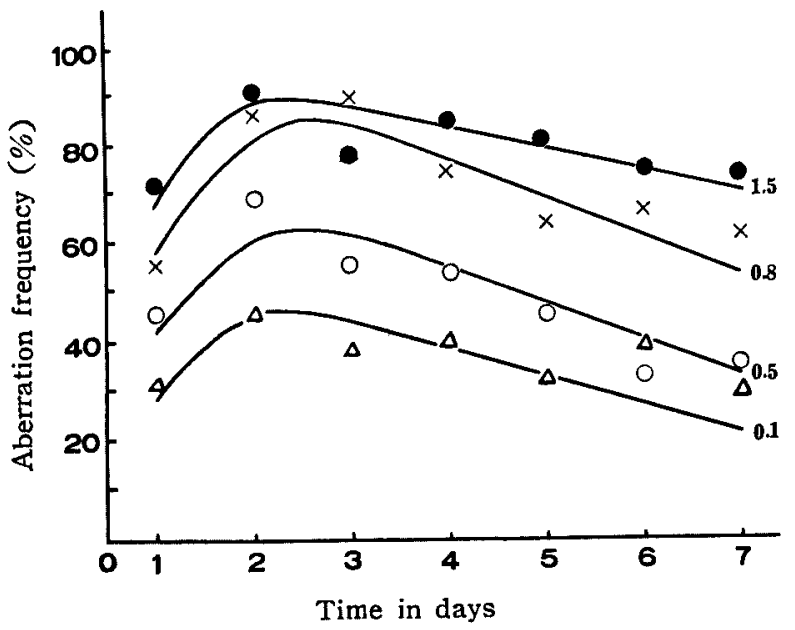

Fig. 13. Relation between frequency of anaphase irregularity and time after $\mathbf{P}^{32}$ treatment (Method I). 
all cases is shown two or three days after treatment.

2. Abberrations induced by Method II (Radicle immersion).

Varrious chromosme abrrations scored by this method are listed in Tables 5 and 6. The frequencies of aberrations in the meiosis were far lower than those obtained with Method I even when they were fifteen per cent at MI as the maximum frequency of maximum radioactivity of $1.2 \mu \mathrm{c}$ (Table 5). Aberration types observed in

Table 5. Frequencies of chromosome aberrations at MI induced by Method II (Radicle immersion).

\begin{tabular}{|c|c|c|c|c|c|c|c|c|c|}
\hline \multirow{2}{*}{$\begin{array}{l}\text { Initial } \\
\text { activity } \\
\text { (p.c./ml.) }\end{array}$} & \multirow{2}{*}{$\begin{array}{l}\text { Num, of } \\
\text { PMC } \\
\text { observed }\end{array}$} & \multirow{2}{*}{$\begin{array}{c}\text { Num. of } \\
\text { normal } \\
\text { PMC }\end{array}$} & \multicolumn{6}{|c|}{ Num. of PMC with aberratinns } & \multirow{2}{*}{$\%$} \\
\hline & & & Type 1 & Type 2 & Type 3 & Type 4 & Type $5^{1 /}$ & Total & \\
\hline 1.2 & 120 & 102 & 4 & 3 & 2 & 7 & $2(B)$ & 18 & 15.0 \\
\hline 0.6 & 203 & 182 & 6 & 2 & 3 & 10 & 0 & 21 & 10.3 \\
\hline Cont. & 210 & 210 & 0 & 0 & 0 & 0 & 0 & 0 & 0.0 \\
\hline
\end{tabular}

1) See Table 2.

the present experiment were similar to those MI and AI treated with Method I, i.e metaphase and anaphase irregularities were marked. At MI. chains, rings and frying-pans formed by chromosome interchange were often seen, but the occurrences of fragments or minutes were relatively few.

An interesting observation was that a side view of the same figure in early anaphase, revealed that both parts of a normal bivalent had already separated, moving toward opposite poles, while separation of a large chromosome ring was delayed. Of the anaphase irregularities, laggard chromosomes (Type I) were more frequent (Table 6), with a small number showing bent spindles. Bent sticky bridges, large

Table 6. Frequencies of aberrations at AI induced by Method II (Radicle immersion).

\begin{tabular}{|c|c|c|c|c|c|c|c|c|c|}
\hline \multirow{2}{*}{$\begin{array}{c}\text { Initial } \\
\text { activity } \\
(\mu \mathrm{c} . / \mathrm{ml} \text { ) }\end{array}$} & \multirow{2}{*}{$\begin{array}{c}\text { Num. of } \\
\text { PMC } \\
\text { observed }\end{array}$} & \multirow{2}{*}{$\begin{array}{l}\text { Num. of } \\
\text { normal } \\
\text { PMC }\end{array}$} & \multicolumn{6}{|c|}{ Num. of PMC with aberrafions } & \multirow{2}{*}{$\%$} \\
\hline & & & Type 1 & Typl 2 & Type 3 & Type 4 & Type $5^{11}$ & Total & \\
\hline 1. 2 & 115 & 99 & 8 & 3 & 2 & 2 & $1(B)$ & 16 & 13.8 \\
\hline 0.6 & 150 & 113 & 13 & 0 & 1 & 7 & $1(\mathrm{~A})$ & 22 & 14.6 \\
\hline Cont. & 170 & 170 & 0 & 0 & 0 & 0 & 0 & 0 & 0.0 \\
\hline
\end{tabular}

1) See Table 3.

acentric fragments and minutes were also found, but such aberrations were comparatively rare. Abnormal cleavages were in the tetrad stage.

3. Aberrations induced by Method III (Leaf immersion).

Results obtained with this method are given in Tables 7 and 8 . The present frequency was found to be far higher as compared with that induced with Method II, despite the use of the same $\mathrm{P}^{32}$ activity in both cases $(0.6$ and $1.2 \mu \mathrm{c})$.

Various aberration types observed at MI were strikingly like those treated with Methods I and II described above, i.e. chains, rings and frying-pans were more fre- 
Table 7. Frequencies of chromosome aberrations at MI induced by Method III (Leaf immersion).

\begin{tabular}{|c|c|c|c|c|c|c|c|c|c|}
\hline \multirow{2}{*}{$\begin{array}{c}\text { Initial } \\
\text { activity } \\
(\mu \mathrm{c} . / \mathrm{ml} .)\end{array}$} & \multirow{2}{*}{$\begin{array}{l}\text { Num. of } \\
\text { PMC } \\
\text { observed }\end{array}$} & \multirow{2}{*}{$\begin{array}{l}\text { Num. of } \\
\text { normal } \\
\text { PMC }\end{array}$} & \multicolumn{6}{|c|}{ Num. of PMC with aberrations } & \multirow{2}{*}{$\%$} \\
\hline & & & Type 1 & Type 2 & Type 3 & Type 4 & Type $5^{11}$ & Total & \\
\hline 1.2 & 93 & 24 & 16 & 9 & 11 & 31 & $2(2 B)$ & 69 & 74.2 \\
\hline 0.6 & 105 & 61 & 8 & 4 & 5 & 27 & 0 & 44 & 41.9 \\
\hline Cont. & 100 & 100 & 0 & 0 & 0 & 0 & 0 & 0 & 0.0 \\
\hline
\end{tabular}

1) See Table 2.

Table 8. Frebuencies of aberrations at AI induced by Method III (Leaf immersion).

\begin{tabular}{|c|c|c|c|c|c|c|c|c|c|}
\hline \multirow{2}{*}{$\begin{array}{c}\text { Initial } \\
\text { activity } \\
\text { ( } \mu . \mathrm{c} . / \mathrm{ml} .)\end{array}$} & \multirow{2}{*}{$\begin{array}{l}\text { Num. of } \\
\text { PMC } \\
\text { observed }\end{array}$} & \multirow{2}{*}{$\begin{array}{l}\text { Num. of } \\
\text { normal } \\
\text { PMC }\end{array}$} & \multicolumn{6}{|c|}{ Num. of PMC with aberrations } & \multirow{2}{*}{$\%$} \\
\hline & & & Type 1 & Type 2 & Type 3 & Type 4 & Type $5^{11}$ & Total & \\
\hline 1.2 & 75 & 18 & 39 & 6 & 5 & 4 & $3(2 \mathrm{~A}, \mathrm{C})$ & 57 & 76.0 \\
\hline 0.6 & 92 & 41 & 30 & 3 & 9 & 7 & $2(\mathrm{~A}, \mathrm{~B})$ & 51 & 55.4 \\
\hline Cont. & 89 & 89 & 0 & 0 & 0 & 0 & 0 & 0 & 0.0 \\
\hline
\end{tabular}

1) See Table 3.

quently seen. Paired fragments or minutes produced by isochromatid break were clearly seen. "A" chromosome always appeared stable for the breaks of radiation. A large polycentric ring with many spindles and, also, a formation of tripolar spindles were observed. Occasionally there were two interlocking frying-pans.

In ealy anaphase, large rings consisting of many chromosomes separated to form a zig-zag pattern. Of anaphase irregularities, cells with laggard chromosomes (Type I) were more numerous than other cells. Bridges with a bent spindle or with sticky fragments or minutes were also found; fragments or minutes were usually converted into micronuclei in the cytoplasm in the late anaphase. Aberrations in the second division and abnormal cleavages in tetrad stage were additionally marked. Abnormal pollen grains were more productive.

\section{Discussion}

Experiments of Giles (1947), Giles and Bolomey (1948) on Tradescantia and of Arnason (1948), Arnason et al. (1948) on wheat, have shown that absorbed $\mathrm{P}^{32}$ and $\mathrm{C}^{14}$, both producing $\beta$-rays, do produce abundant chromosome breaks and structural changes. They concluded that the sequence of chromosome aberration types induced by internal $\beta$-radiation is fundamentally the same as that induced by X-rays. Thus it seems likely that abundant abnormal configurations, such as chromosome rings, chains and frying-pans observed in this experiments, were formed by segmental interchanges between nonhomologous chromosomes.

Comparisons of frequencies of aberrations obtained by the three different methods desribed above, are depicted graphically in Figures 14 (MI) and 15 (AI) respectively. In both figures, the aberrations induced by Method I (stem injection) are represented 


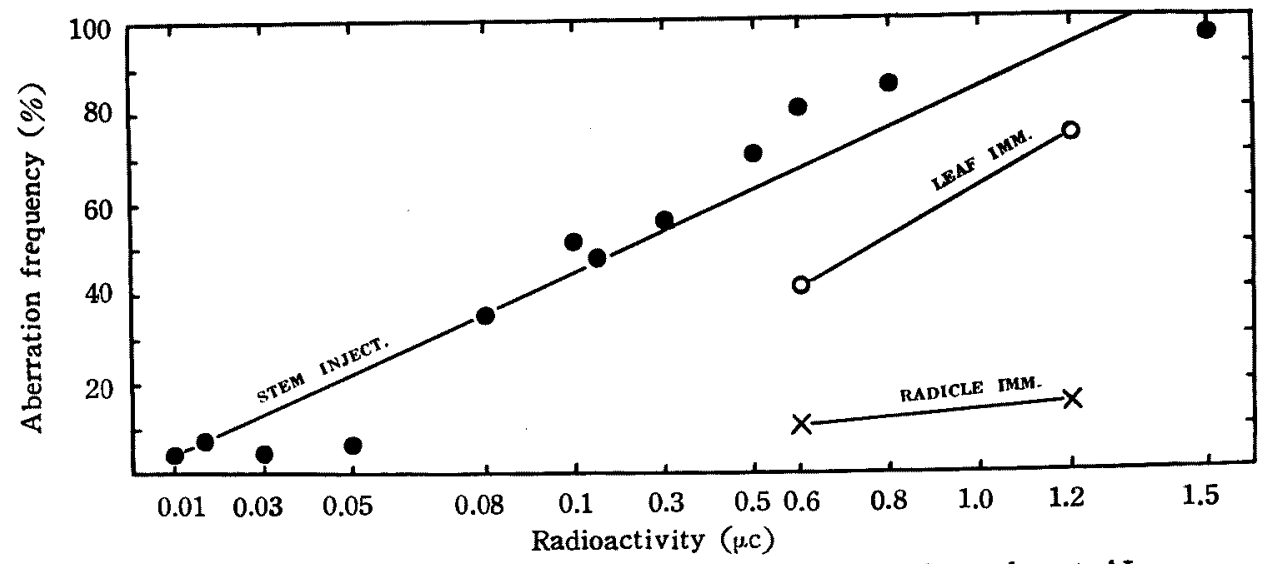

Fig. 15. Relation between radioactivity and aberration frequedcy at Al.

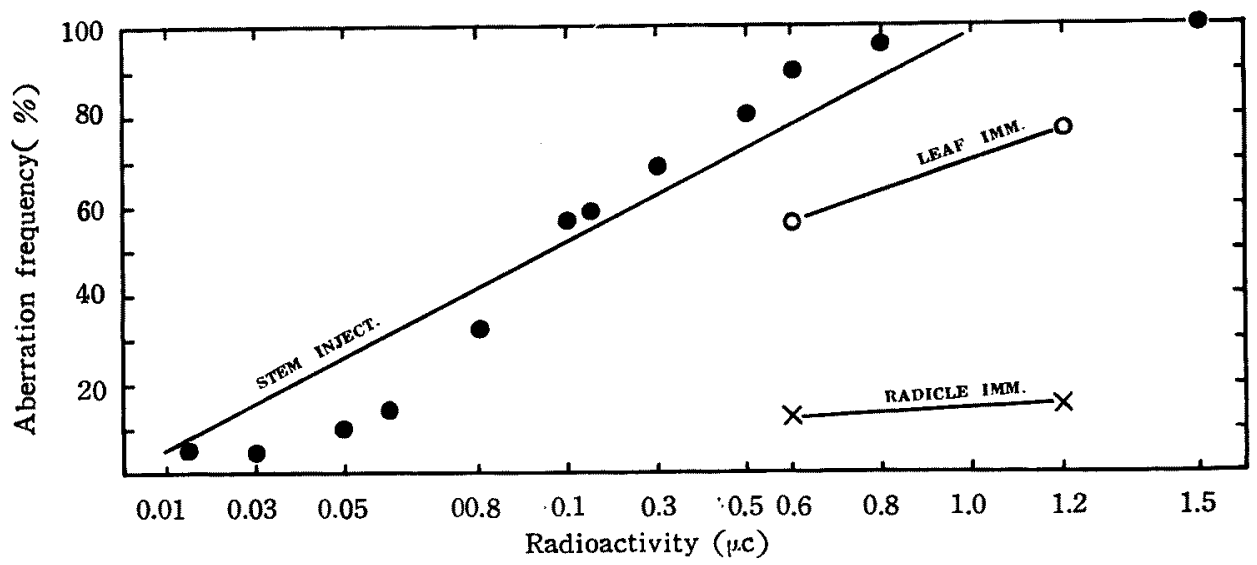

Fig. 14. Relation between radioactivity and aberration frequedcy at MI.

by a regression while those induced by Methods II and III are represented by the actual value of the observations. As shown in Figures 14 and 15, for Method I, at least, it is indicated that the relationship between dosage (radioactivity) of $\beta$-rays and the frequency of aberrations besed on a regression analyse was linear. In general, aberration frequency at AI was found to be high as compared with that at MI, except only for the one case $(15.0 \%)$ at MI treated with Method II.

This difference in aberration frequency scored at MI and AI, may be due to the existence of chromosomes which, because of the very small size of the meiotic chromosomes examined in the material, would be difficult or impossible to detect morphologically as certain aberrations at MI, such as miunte deficiencies, incomplate breaks or inactivations of centromere, etc. If so, such affected chromosomes would show abnormalities as laggard chromosomes, acentrics, etc. in their anaphase separation, in spite of the fact that they were observed as normal at their MI. In consequence, the aberration frequency at AI must have been higher than that at MI. On this point, there are some reports of regional differerces in the sersitivity of chrorrosomes of ionizing radiations. Sax (1946) has shown that X-ray breaks in Trades- 
cantia are very frequent in the region near the centromere. In the plant Solanum, Gottschalk (1951) found the centromere gegion to be especially sensitive ( $82.2 \%)$ to $\mathrm{X}$-ray breakage, and he also observed a higher breakage frequency in the heterochromatin segments than in the euchromatin regions. Recently, Rees and Thompson (1955) stated that at meiosis in a strain of inbred rye, breakage is localised mainly away from the centromeres towards the end of the chromosomes, closely related to distribution of chiasmata.

In the present observations, chromosome " $\mathrm{A}$ " often exhibited a certain stability for the $\beta$-ray breaks. If we adapt the assumption that breakage occurs more often in heterochromatin segments than in those of euchromatin, as mentioned above, we must suggest that chromosome "A" consists of many euchromatin segments.

Thus from these results we can conclude that these methods, especially Method $\mathrm{I}$, is favorable for production of mutations in Sesame.

\section{Summary}

Flower buds of sesame plant (Sesamum indicum L.) were internally subjected to $\beta$-rays from absorbed radiophosphorus $\left(\mathrm{P}^{32}\right)$ by using three different methods, stem injection, radicle immersion and leaf immersion.

The applied radioactivity ranged from 0.005 to $1.5 \mu \mathrm{c}$ per $\mathrm{ml}$. at the start of experiment.

The effects of $\beta$-rays emitted from $\mathrm{P}^{32}$ on living cells were measured by observations on the meiotic chromosome aberrations of the treated plants, and aberration frequency obtained proved to be proportional to dosage of $\beta$-rays.

Aberrations at MI, chromosome chains, rings and frying-pans were more frequently observed, and those at AI laggard chromosomes or acentric fragments were commonly seen throughout the treatment. Among $\beta$-ray effects were fragmentation, bridge, stickiness, formation of multipolar spindles and others.

Cells in tetrad stage, or pollen grains from treated plants exhibited many abnormalities in size, shape and number.

\section{Acknowlegement}

I am deeply indebted to Professor T. Shimamura for his advice and encouragement thoughout these studies.

\section{References}

Arnason, T.J. 1948: Chromosme breakage induced by absorbed radioactive phosphorus. Cold Spring Harbor Symp. Quant. Biol. 13, 1-5.

Arnason, T. J., et al. 1948: Chromosome breakage in plants induced by absorbed radiophosphorus, $\left(\mathrm{P}^{32}\right)$. Science 107, 198-199.

Giles, N. H. Jr. 1947: Chromosome structural changes in Tradescantia microspores produced by absorbed radiophosphorus. Proc. Natl. Acad. Sci. 33, 283-287. 
Giles, N.H. Jr. 1947 and Bolomey, R.A. 1948: Cytogenetical effects of internal radiations from radioisotopes. Cold Spring Harbor Symp. Quant. Biol. 13, 104-112.

Gottschalk, W. 1951: Untersuchungen am pachytän normaler und röntgenbestrahlter Pollenmutterzelien von Solanum lycopersicum. Chromosoma 4, 298-341.

Kobayashi, T. and Shimamura, T. 1952: Morphological and cytological studies on induced polyploidy in Sesamum indicum L. Jap. Jour. Genet. 27, 159-171.

Kobayashi, T. 1954a: Effects of radioactive phosphorus ( $\mathrm{P}^{32}$ ) upon the nuclear division in plant cells (Japanese). Radioisotopes 3, 15-17.

Kobayashi, T. 1954b: Action of Radioactive substances on the plant cells 1 . The abnormal nuclear division induced by internal radiation of $\beta$-rays. (Japanese). Jap. Jour. Genet. $29,161$.

Kobayashi, T. 1955: Some new characters of sesame induced by radiation treatments (Japanese). Jap. Jeur. Breeding. 5, Suppl. 39.

Koller, P.C. 1953: The cytological effects of irradiation at low intansities. Heredity 6, Suppl. 5-22.

Koller, P.C. 1954: Chromosome breakage. Progress in Biophysics and Biophysical Chemistry 4, 195-243.

Lea, D. E. 1946: Actions of radiation on living cells. McMillan Co., New York.

Rees, H. and Thompson, J.B. 1955: Localisation of chromosome breakage at meiosis. Heredity 9, 399-407.

Sax, K. 1938: Chromosome aberations induced by X-rays. Genetics 66, 84-87.

Sax, K. 1940: An analysis of X-ray induced chromosomal aberrations in Tradescantia. Cenetics $25,41-68$.

\section{Explanation of Plate}

\section{PLATE I.}

Figs. 1-4. $\mathrm{P}^{32}$ autoradiographs obtained from a plant treated with Method $I$ (1.5 weeks exposure by contact method).

1-2. A young leaf with flower buds in each. Note the radioactivity in the anthers and in the ovary ca. $\times 2$.

3. Two flower buds at the axil. ca. $\times 2$.

4. Anthers, filaments and the base of corolla. $\times 2$.

Fig. 5. $\mathbf{P}^{32}$ autoradiographs of longitudinal sections of seedling treated with method II (1.2 $\mu \mathrm{c}$, three weeks exposure by contact method). ca. $\times 2$.

Fig. 6. $\mathrm{P}^{32}$ autoradiograph obtained from the leaf treated with Method III. Black pores show broken parts in the process of the technique $(1.2 \mu \mathrm{c}$, one week exposure by contact method). $\times 1$.

\section{PLATE II.}

Figs. 7-17. Photomicrographs of meiotic chromosomes and pollen grains of sesame showing the major types of aberrations induced by Method I (Figs. 7-15: $\times 1800$, Fig.16: $\times 180$, Fig. 17: $\times 100)$.

Figs. 7-13. Metaphase I.

7. Untreate 1 , thirteen normal chromosomes (13II) at MI. The " $A$ " chromosome is indicated by $A$.

8. $(-6-)+(-4-)+7$ II and two fragments (indicated by arrow) causing isochromatid break $0.5 \mu \mathrm{c})$.

9. (10) $-14-+1$ II $(\mathrm{A})(0.6 \mu \mathrm{c})$.

10. Twe rings : (14) $+(12)(0.8 \mu \mathrm{c})$.

11. (29) $(0.8 \mu \mathrm{c})$.

12. A mass produced by fusion of all complements $(1.5 \mu \mathrm{c})$.

13. Formation of tripolar spindles $(0.08 \mu \mathrm{c})$.

Figs. 14-15. Anaphase I.

14. Single and double bridges, and acentric fragment $(0.3 \mu \mathrm{c})$.

15. Two fragments excluded at late anaphase $(0.1 \mu \mathrm{c})$.

Fig. 16. Six pollen grains produced by irregular cleavage $(0.6 \mu c)$.

Fig. 17. Cross section of the anther treated with $0.8 \mu \mathrm{c}$. There are some abortive pollen sacs resulting degenerations of tapetal cells. 
Plate I.

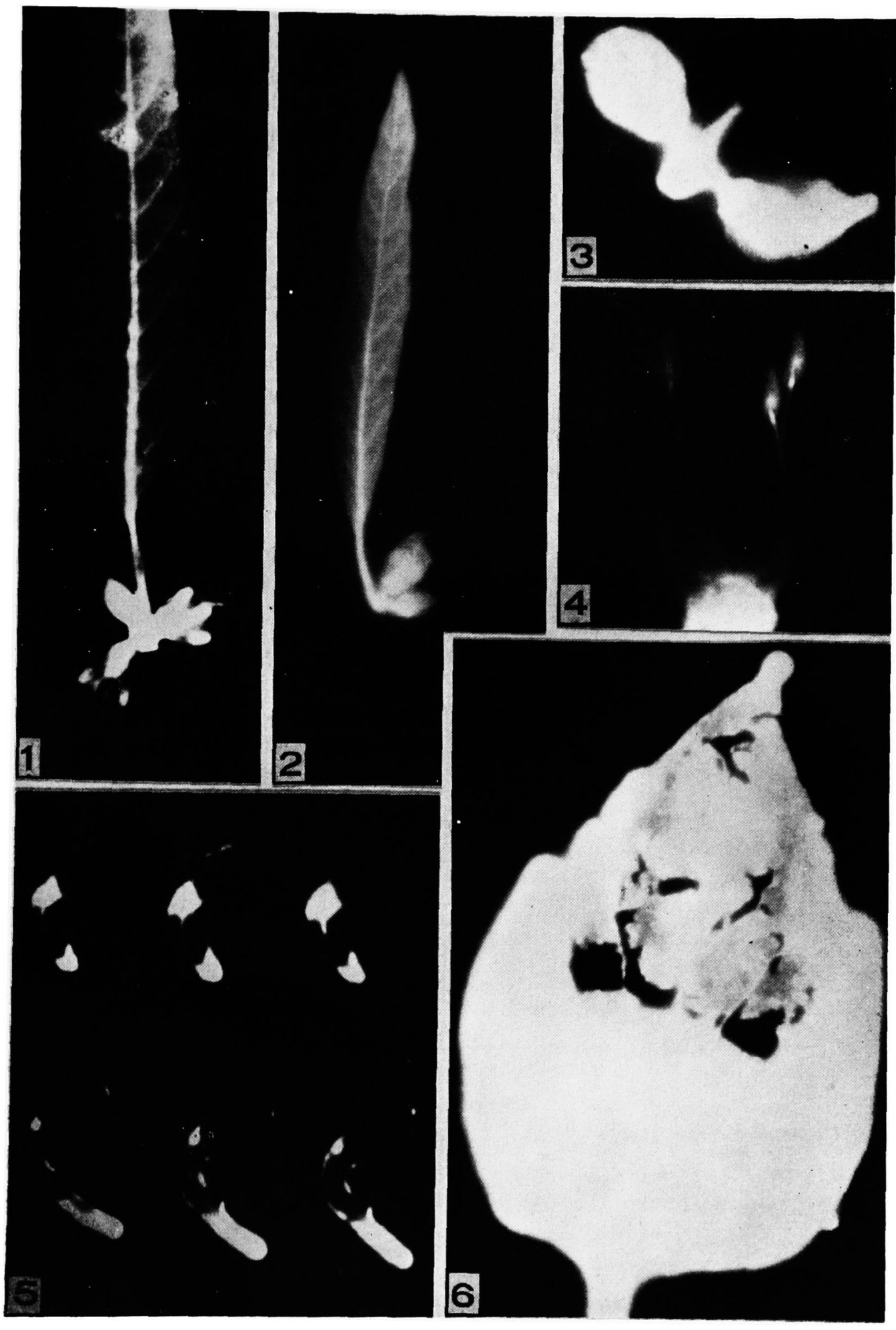


Plate II.

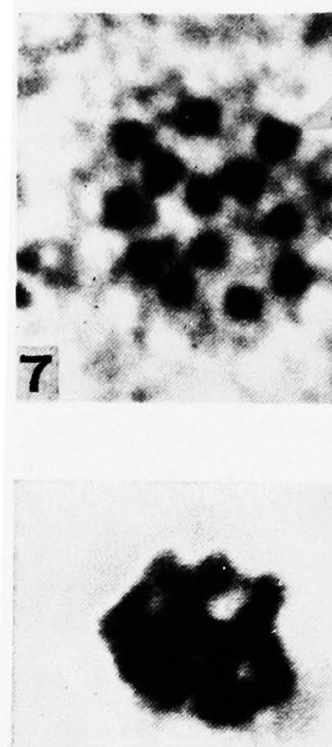

10

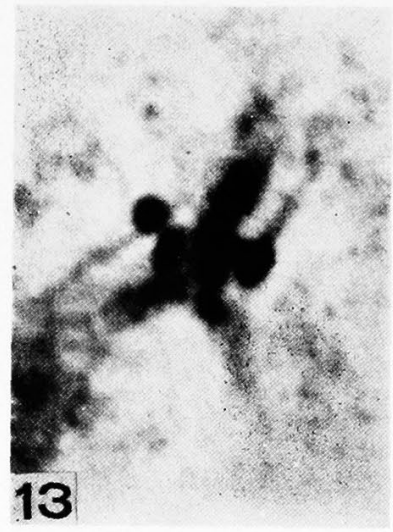

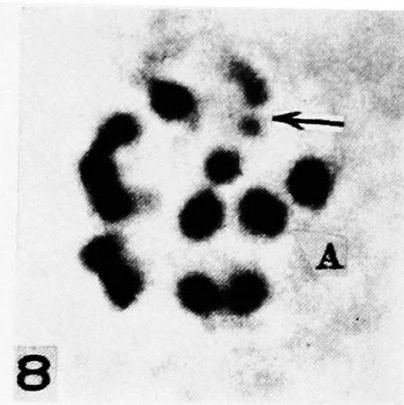



11

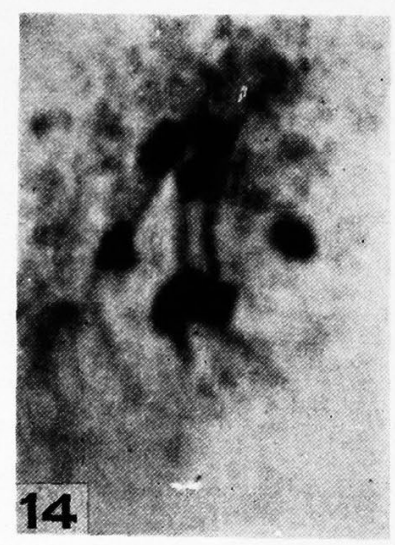



9

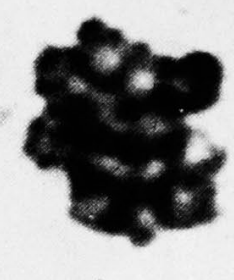

12

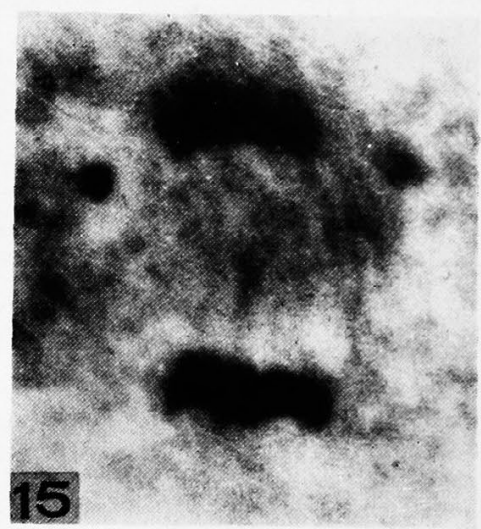

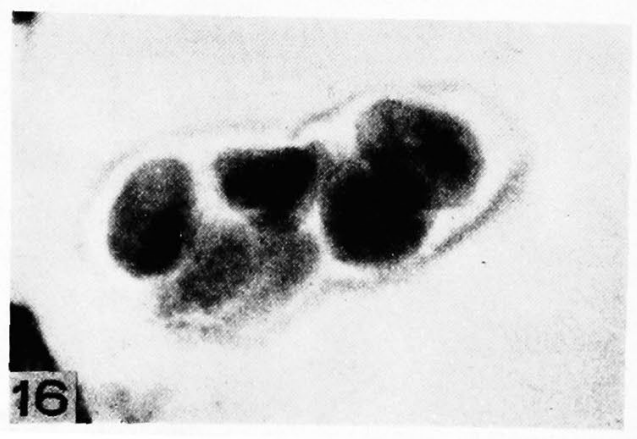



